\title{
Adaptive Immunity and Pathogenesis of Diabetes: Insights Provided by the $\alpha 4$-Integrin Deficient NOD Mouse
}

\author{
Salim Oulghazi ${ }^{1,+}{ }^{\oplus}$, Sarah K. Wegner ${ }^{1}$, Gabriele Spohn ${ }^{2}$, Nina Müller ${ }^{2}$, Sabine Harenkamp ${ }^{2}{ }^{\infty}$, \\ Albrecht Stenzinger ${ }^{3}$, Thalia Papayannopoulou ${ }^{4}$ and Halvard Bonig $1,2,4, *$ (I) \\ 1 Institute for Transfusion Medicine and Immunohematology, School of Medicine, Goethe University, \\ Sandhofstraße 1, 60528 Frankfurt, Germany; salim_oulghazi@hotmail.com or \\ salim.oulghazi@med.uni-heidelberg.de (S.O.); sarah.k.wegner@outlook.de (S.K.W.) \\ 2 Institute Frankfurt, German Red Cross Blood Service BaWüHe, Sandhofstraße 1, 60528 Frankfurt, Germany; \\ g.spohn@blutspende.de (G.S.); n.mueller85@gmx.de (N.M.); s.harenkamp@blutspende.de (S.H.) \\ 3 Institute for Pathology, University Hospital Heidelberg, Im Neuenheimer Feld 672, 69120 Heidelberg, \\ Germany; Albrecht.Stenzinger@med.uni-heidelberg.de \\ 4 Department of Medicine/Division of Hematology, University of Washington, 1959 NE Pacific St., Seattle, \\ WA 98195, USA; thalp@uw.edu \\ * Correspondence: hbonig@uw.edu; Tel.: +49-69-6782177 \\ + Current address: Department of Internal Medicine V (Hematology/Oncology/Rheumatology), \\ University Hospital Heidelberg, Im Neuenheimer Feld 672, 69120 Heidelberg, Germany.
}

Received: 11 November 2020; Accepted: 2 December 2020; Published: 4 December 2020

\begin{abstract}
Background: The spontaneously diabetic "non-obese diabetic" (NOD) mouse is a faithful model of human type-1 diabetes (T1D). Methods: Given the pivotal role of $\alpha 4$ integrin (CD49d) in other autoimmune diseases, we generated NOD mice with $\alpha 4$-deficient hematopoiesis (NOD. $\alpha 4-/-)$ to study the role of $\alpha 4$ integrin in T1D. Results: NOD. $\alpha 4-/-$ mice developed islet-specific T-cells and antibodies, albeit quantitatively less than $\alpha 4+$ counterparts. Nevertheless, NOD. $\alpha 4-/-$ mice were completely and life-long protected from diabetes and insulitis. Moreover, transplantation with isogeneic $\alpha 4-/$ - bone marrow prevented progression to T1D of pre-diabetic NOD. $\alpha 4+$ mice despite significant pre-existing islet cell injury. Transfer of $\alpha 4+/ C D 3+$, but not $\alpha 4+/ C D 4+$ splenocytes from diabetic to NOD. $\alpha 4-/-$ mice induced diabetes with short latency. Despite an only modest contribution of adoptively transferred $\alpha 4+/ C D 3+$ cells to peripheral blood, pancreas-infiltrating T-cells were exclusively graft derived, i.e., $\alpha 4+$. Microbiota of diabetes-resistant NOD. $\alpha 4-/-$ and pre-diabetic NOD. $\alpha 4+$ mice were identical. Co- housed diabetic NOD. $\alpha 4+$ mice showed the characteristic diabetic dysbiosis, implying causality of diabetes for dysbiosis. Incidentally, NOD. $\alpha 4-/-$ mice were protected from autoimmune sialitis. Conclusion: $\alpha 4$ is a potential target for primary or secondary prevention of T1D.
\end{abstract}

Keywords: VLA4; CD49d; type-1-diabetes; autoimmune diabetes; sialitis; integrin

\section{Introduction}

The increasing incidence and decreasing age at onset of autoimmune type-1 diabetes (T1D) [1,2] reinforces the need for a causal therapeutic intervention since euglycemia, which is always challenging to maintain with insulin replacement, is notoriously difficult to achieve in young children because of irregular life-styles, growth spurts and frequent, otherwise banal febrile infections [3,4]. When T1D is first diagnosed, significant residual islet cell mass remains [5,6] and islet cells possess relevant regenerative potential $[7,8]$. Interventions arresting the autoimmune process at this stage could 
therefore potentially still be curative [9]. Alternatively, the appearance of islet autoantibodies, sensitive harbingers of T1D development [10], in siblings of patients with T1D could trigger the initiation of islet-preserving therapies during pre-diabetes.

The adhesion molecules very late antigen-4 (VLA-4), a heterodimer of the $\alpha 4$ (CD49d) and the $B 1$ (CD29) integrins, and, to a lesser degree, LPAM-1 ( $\alpha 4 / B 7)$ have been identified as exquisite targets for immune modulation in a number of autoimmune disease models [11-14], as well as in select clinical indications, namely refractory multiple sclerosis (MS) and inflammatory bowel disease (IBD) [15-17]. Indeed anti-functional $\alpha 4$ antibodies were also studied in the NOD mouse, a faithful model of human T1D. Evidence was provided that neutralizing anti- $\alpha 4$ rat-anti-mouse antibodies could delay, attenuate penetrance, or outright prevent T1D development [18-21]. Two basic experimental constellations were tested. Either NOD mice were transiently treated with anti-functional anti- $\alpha 4$ antibodies, where earlier onset of treatment and longer treatment duration seemed to affect the efficacy of the intervention [19-21]. Alternatively, diabetogenic NOD T-cells incubated with anti- $\alpha 4$ antibodies were adoptively transferred into isogeneic NOD/SCID (severe combined immunodeficiency) mice followed by further antibody treatment of the recipients. This approach similarly delayed T1D or reduced its incidence [18]. Three studies, all by the same group, addressed the role of $\alpha 4$ for NOD autoimmune sialitis; in their experimental set-up, function-blocking anti- $\alpha 4$ antibody was ineffective; the paradigm of $\alpha 4$ independence of NOD autoimmune sialitis is based entirely on this limited set of studies $[19,22,23]$. Several additional important questions could not be addressed in these models, in part due to limitations of the model per se, in part due to new technologies which have arisen since the execution of these seminal experiments. We therefore generated NOD mice deleted for $\alpha 4$ in the hematopoietic lineage (NOD. $\alpha 4-/-)$ to study T1D and sialitis development and some related questions.

\section{Materials and Methods}

Mice: Diabetes-prone NOD/ShiLtJ mice (NOD) were purchased from Jackson Laboratories (Bar Harbor, ME). NOD. $\alpha 4 f / f T i e 2 c r e+$ mice ( $\alpha 4$-ablator mice) were generated by separately back-crossing NOD mice with the previously described C57Bl/6. $\alpha 4 \mathrm{f} / \mathrm{f}$ [24] and C57Bl/6.Tie2cre+ [25] mice. In the first generation, NOD males were used, to fix the Y-chromosome, in all future generations, mixed male offspring were crossed with NOD females. After 10 generations, whole genome screening for genetic purity was performed (Jackson Laboratories). Confirmed NOD. $\alpha 4 \mathrm{f} /+$ and NOD.cre+ mice were crossed to generate ablators. Genotyping was completed on ear punch DNA using a conventional 3-primer strategy [24]; all putatively $\alpha 4$-deficient mice were additionally phenotyped in blood using flow cytometry. Throughout this manuscript, we will refer to all $\alpha 4$-homozygous NOD mice, whether $\alpha 4+/+$ (irrespective of cre status), $\alpha 4 \mathrm{f} /+$ cre- or $\alpha 4 \mathrm{f} / \mathrm{fcre}-$, as "NOD" or "NOD. $\alpha 4+$ ", to $\alpha 4 \mathrm{f} /+\mathrm{cre}+$ mice as " $\alpha 4$ haploinsufficient", and $\alpha 4 \mathrm{f} / \mathrm{fcre}+$ as "NOD. $\alpha 4-/-$ ". To observe spontaneous occurrence of T1D in our cohort, female NOD, haploinsufficient NOD or NOD. $\alpha 4-/-$ mice were continuously recruited until 20 NOD. $\alpha 4-/-$ mice had been accrued. For adoptive T-cell transfer experiments, splenocytes of diabetic NOD mice were bluntly extruded, red blood cells (RBC) lysed in hypotonic buffer, washed and immunomagnetically enriched using Miltenyi directly conjugated antibody-bead complexes, CD3-negative selection (Pan T Cell Kit II) or CD4-positive selection (CD4 microbeads) and AutoMACS according to manufacturer's instructions (selection reagents and technology Miltenyi, Bergisch-Gladbach, Germany). Isogeneic recipients, all females aged 8-10 weeks, $\alpha 4$-competent or not, received 650 cGy irradiation for lymphodepletion, followed by i.v. injection of $5 \times 106 \mathrm{CD} 3+$ or $2.5 \times 106$ CD4+ splenic T-cells, as previously described [15]. Transplantation used $\alpha 4$-competent 10-12 week-old pre-diabetic NOD recipients who received lethal irradiation of $1050 \mathrm{cGy}$ followed by i.v. transplants of $2 \times 106$ NOD or $10 \times 106$ NOD. $\alpha 4-/$ - bone marrow (BM) cells in a volume of $200 \mu \mathrm{L}$, as previously reported [24]. Peritransplant, drinking water was prophylactically supplemented with $0.02 \%$ Baytril (Bayer, Leverkusen, Germany) [26]. Wherever donor cells were used, cells from 3-5 donors were pooled to reduce effects of inter-individual variability. Blood glucose level was tested weekly for spontaneous diabetes cohorts (starting week 8 for untreated and week 4 after transplantation for transplanted mice) 
and thrice weekly after T-cell transfer (starting 1 week after transfer) (ACCU-CHECK Aviva hardware and consumable; Roche Diabetes Care, Mannheim, Germany). Diabetes was diagnosed based on any blood glucose level $>200 \mathrm{mg} / \mathrm{dL}$ on two consecutive days [15]. Prior to stool sampling, mice from the different cohorts (pre-diabetic NOD, diabetic NOD, NOD. $\alpha 4-/-)$ were co-housed for at least one week, thereafter separated for 48 hours and from each of the mice all stool pellets were collected into sterile $1.5 \mathrm{~mL}$ tubes which were shock-frozen at $\leq-80{ }^{\circ} \mathrm{C}$ and shipped to the Mouse Metabolic Phenotyping Center, University of California, Davis, California (MMPC). Unless otherwise noted, mice were kept in groups of up to 5 mice per cage in the vivarium of Goethe University School of Medicine under conventional (non-specific pathogen-free) conditions in filter top cages with food and water ad libitum. Mouse experiments were guided by the RRR principles, followed the Association for Assessment and Accreditation of Laboratory Animal Care International (AAALAC) guidelines for humane mouse experimentation and were approved by the animal protection authority of the state of Hessen (approval \#F27/K5452).

Cellular immune system: blood was drawn from the facial vein of diabetic $\alpha 4$ - competent NOD control mice or from 20-week-old female NOD. $\alpha 4-/-$ mice; after RBC-lysis, peripheral blood leukocytes were stained with anti-CD45/anti-CD3/anti- CD4/anti-CD8/anti-CD44/anti-CD62L (to distinguish in the CD4+ and CD8+ compartments naïve, memory and effector cells) [27,28], as well as anti-CD335 (to detect NK-cells) [29] (all antibodies (ABs) directly fluorochrome labeled, all ABs Biolegend, Amsterdam, the Netherlands), washed and re-suspended in 7AAD-containing FACS buffer for acquisition and analysis on an LSR Fortessa flow cytometer (Becton-Dickinson). For detection of antigen-specific T- cells, lysed peripheral blood was co-stained with anti-CD45, anti-CD3 and anti-CD8 directly fluorescence-labeled antibodies (all Becton-Dickinson, Heidelberg, Germany) as well as phycoerythrin (PE)-labeled major histocompatibility (MHC)-I dextramer H-2Kd/VYLKTNVFL (from islet-specific glucose-6-phosphatase catalytic subunit-related protein, IGRP) according to manufacturer's recommendations (Immudex, Copenhagen, DK) for acquisition/analysis on LSR Fortessa [30]. The same stainings with leukocytes from MHC-disparate C57Bl/6 mice served to establish the level of unspecific background staining (negative controls). The frequencies shown for antigen-specific CD8+ T-cells in the NOD or NOD. $\alpha 4-/-$ mice are corrected by subtracting mean background staining from negative controls.

Humoral immune system: B-cell subtypes in BM, spleen and blood were distinguished by flow cytometry using established antibody panels (anti-CD45/anti-B220/anti-CD24/anti-CD43/ anti-IgD/anti-IgM (for detection of surface $\operatorname{IgD} / \operatorname{IgM}$ ) [31,32]. To generate benchmarking data for the capacity of the $\alpha 4$-deficient immune system, mice received three weekly i.m. injections of $1 \mu \mathrm{g}$ recombinant Hepatitis B surface antigen (HBs) vaccine HBVAXPRO (axicorp Pharma GmbH, Friedrichsdorf, Germany) and a booster injection in week 12, and anti-HBs titers were measured in mouse EDTA plasma 1:3 diluted in PBS after 4, 11 and 13 weeks using the ARCHITECT anti-HBs chemiluminescent microparticle immunoassay on the ARCHITECT i1000SR (Abbott, Wiesbaden, Germany) according to the manufacturer's instructions. Anti-insulin autoantibodies were measured in mouse EDTA plasma using the IAA sandwich ELISA (Elabscience Biotechnology, Houston, Texas, USA) on the VICTOR X4 multiplate reader (Perkin-Elmer, Rodgau, Germany) as directed by the manufacturer.

Preparation of pancreas-infiltrating lymphocytes: Immediately post-mortally, the pancreas was located, the jejunum was clamped proximally and distally of the major papilla and collagenase IV buffer (1 mg/mL in 4-(2-hydroxyethyl)-1-piperazineethanesulfonic acid (HEPES)) was injected via the gall bladder. The pancreas was removed into collagenase IV buffer, digested for $15 \mathrm{~min}$ in a $37^{\circ} \mathrm{C}$ water bath with occasional agitation, subsequently shaken to generate a homogenous cell dispersion. An excess of HEPES without collagenase was added and the suspension abruptly cooled to stop the digest, cells were washed twice, then filtered through a $70 \mu \mathrm{m}$ filter. Under a microscope islets were picked into Roswell Park Memorial Institute (RPMI) medium with 10\% fetal bovine serum and Pen/Strep and transferred to a cell culture incubator (standard conditions) to allow overnight 
lymphocyte migration into the medium [33]. Cells were co-stained with directly conjugated CD3 and CD49d antibody for acquisition/analysis on the LSR Fortessa flow cytometer (BD).

Histology and insulitis scoring: pancreata and submandibular glands were prepared from painlessly killed non-diabetic 8 weeks-old, newly diabetic and "chronically" diabetic (three weeks after diabetes onset) $\alpha 4$-competent control NOD mice as well as from 40 weeks-old NOD. $\alpha 4-/-$ mice. They were successively paraformaldehyde-fixed ( $4 \% v / v)$, paraffin-embedded, sectioned into $4 \mu \mathrm{m}$ thick slices, layered on glass slides, hematoxylin-eosin (HE)-stained and analyzed for insulitis and sialitis severity, respectively, using established morphological scores, as described [21]. Briefly, islet without lymphocytic infiltrates were scored as ${ }^{\circ} 0$, minimal focal infiltration as ${ }^{\circ} 1$, peri-islet infiltration of $<25 \%$ as ${ }^{\circ} 2$, peri- and intra-islet infiltration of $<50 \%$ as ${ }^{\circ} 3$, and extensive islet infiltration of $\geq 50 \%$, with or without complete destruction of islet tissue and replacement by fibroblasts as ${ }^{\circ} 4$. Sialitis was scored as number of lymphocyte infiltrates per section [34]. Scoring was blinded and performed by two independent investigators. Immunofluorescence histology used $10 \mu \mathrm{m}$ frozen sections incubated with rabbit-anti-mouse-CD3 (OriGene, Rockville, MD, USA), rat- anti-mouse-Meca32 (BioLegend, San Diego, CA, USA) and goat-anti-rabbit Alexa488, goat-anti-rat Alexa546 and DAPI (all Invitrogen, Carlsbad, CA, USA) using standard protocols. Histological specimens were visualized on an Olympus (Tokyo, JP) BX53 microscope fitted with an Olympus SC30 camera model; image acquisition and analysis were done with cellSens software (Olympus) or with the BZ-X810 All-in- One Fluorescence Microscope, Keyence (Neu Isenburg, Germany) and imaging software BZ-X800 Analyzer. No adjustments except brightness were made.

Microbiota: frozen fecal samples were shipped on dry ice to UC Davis MMPC and Host Microbe Systems Biology Core. Total DNA was extracted using Mo-Bio (now Qiagen, Venlo, The Netherlands) PowerFecal kit. Sample libraries were prepared and analyzed by barcoded amplicon sequencing. In brief, purified DNA was PCR- amplified on the V4 region of the 16S rRNA genes using primers F319 (5'-ACTCCTACGGGAGGCAG CAGT-3') and R806 (5'-GGACTACNVGGGTWTCTAAT-3'). High-throughput sequencing was performed with Illumina MiSeq paired end 250- pb run. The sequencing data were processed using QIIME2 for 16S based microbiota analyses (Qiime2 version 2018.6.0; QIIME2 Development Team (2017)). For quality filtering and feature (OTU) prediction, we used DADA2 [35]. Forward and reverse reads were truncated to 260 and 220 nucleotides, respectively. Representative sequences were aligned using MAFFT [36]. A phylogenetic tree of the aligned sequences was made using FastTree 2 [37]. OTUs/features were taxonomically classified using a pre-trained Naïve Bayes taxonomy classifier. The classifier was trained using the Silva $12897 \%$ OTUs [38] for the 310F-806R region. Tables of taxonomic counts and percentage (relative frequency) were generated. Diversity analyses were run on the resulting OTU/feature biom tables to provide both phylogenetic and non-phylogenetic metrics of $\alpha$ and $B$ diversity [39] Additional data analysis (PLS-DA) and statistics were performed with R. Analyses and bioinformatics were performed by the MMPC.

Statistics: descriptive statistics and Student's $t$-tests, with Bonferroni correction for multiple testing where applicable, were calculated in Excel (Microsoft, Redmond, WA). Non-parametric values were compared using Mann-Whitney's $U$-test calculated with the online tool on www.socscistatistics.com. Kaplan-Meyer statistics were calculated using the log-rank (Mantel-Cox) test in Prism (GraphPad Software, San Diego, CA). With the exception of the experiments shown in Figure 1D and Figure S4, all cohort studies were performed in at least two independent experiments; the cumulative number of animals from all experiments is given either directly in the figure panel or the accompanying legend. A $p<0.05$ was considered statistically significant. 

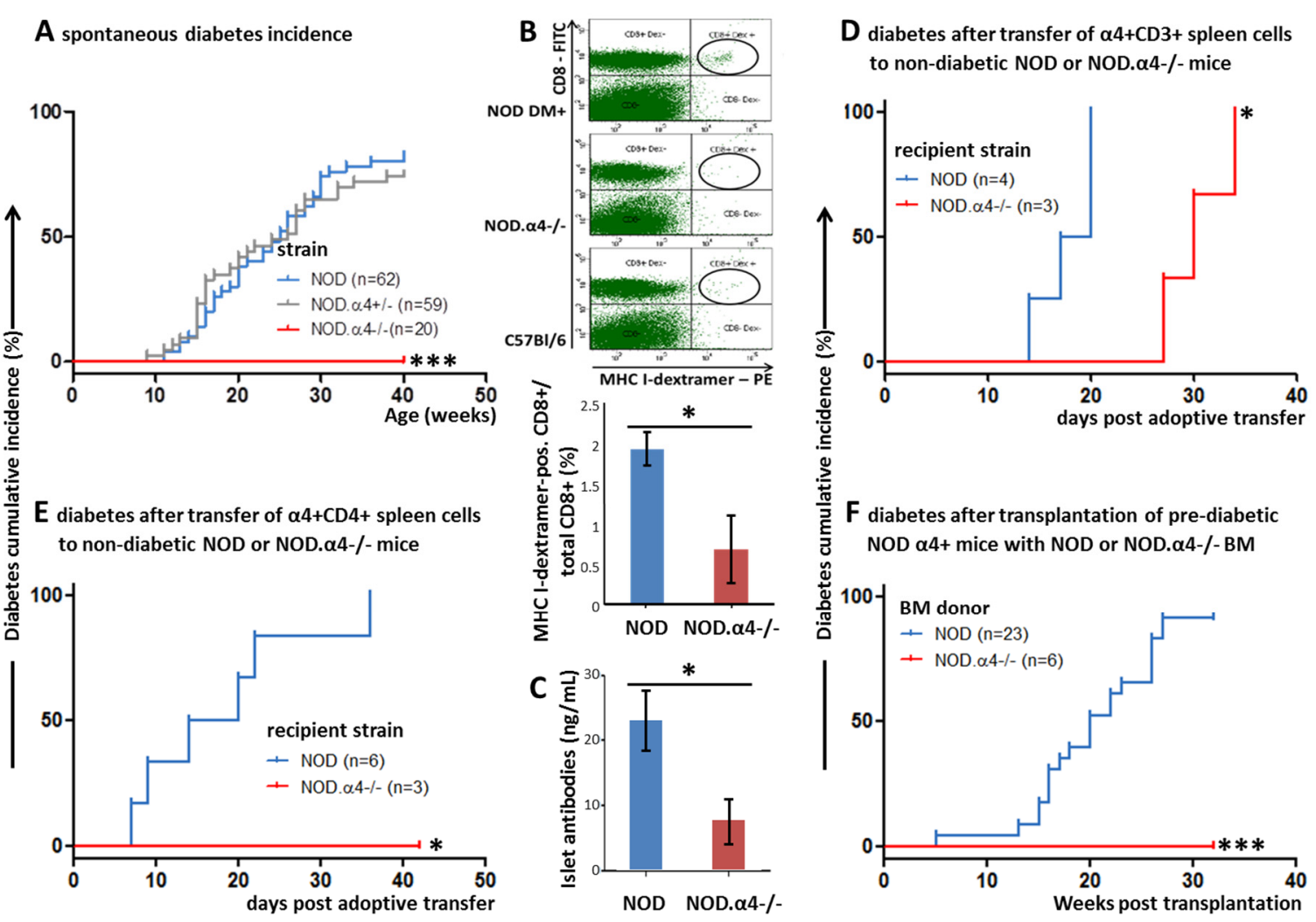

Figure 1. Diabetes and adaptive immune responses against islet antigens. Diabetes was diagnosed on the basis of recurrent hyperglycemia. Spontaneous diabetes development was tracked in $\alpha 4-\mathrm{WT}$ (NOD, blue), $\alpha 4$-haploinsufficient NOD (NOD. $\alpha 4+/-$, grey) and $\alpha 4$-deficient NOD (NOD. $\alpha 4-/-$, red) mice. The cumulative diabetes incidence after 40 weeks in the two $\alpha 4$-competent strains was $82 \%$ (NOD) and $75 \%$ (NOD. $\alpha 4+/-$ ), respectively ( $p=$ n.s.), while none of the NOD. $\alpha 4-/-$ mice developed diabetes ( $p<0.001$ vs. both $\alpha 4$-competent strains) (A). MHC-I dextramer H-2Kd/VYLKTNVFL binding to CD8+ T-cells was assessed by flow cytometry. Shown are representative dot plots for NOD, NOD. $\alpha 4-/-$ and MHC-disparate C57Bl/6 (negative control) mouse blood (upper panel) as well as quantitative analysis (lower panel) where dextramer-positive events in negative control blood were subtracted as background $(n=9$ per group; $p<0.05)(\mathbf{B})$. Anti-insulin autoantibodies were quantified by ELISA $(n=7$ per group; $p<0.05)(C) .5 \times 10^{6} \mathrm{CD} 3+$ splenocytes from diabetic donors were transferred into young adult non-diabetic NOD or NOD. $\alpha 4-/$ - hosts. All recipients became diabetic, but onset of diabetes was significantly delayed in NOD. $\alpha 4-/-$ hosts $(p<0.05)(D) .2 .5 \times 10^{6}$ CD4+ splenocytes from diabetic donors were transferred into young adult non-diabetic NOD or NOD. $\alpha 4-/-$ hosts. NOD rapidly became diabetic, while NOD. $\alpha 4-/-$ were immune $(p<0.05)($ E). Lethally irradiated pre-diabetic young female NOD mice received bone marrow transplants from NOD or NOD. $\alpha 4-/-$ donors. Recipients of NOD bone marrow became diabetic with typical kinetics, while recipients of NOD. $\alpha 4-/$ - bone marrow were protected $(p<0.001)(\mathbf{F})$. Asterisks indicate statistical significance at the $0.05\left(^{*}\right)$ or $0.005\left({ }^{* * *}\right)$ level.

\section{Results}

\subsection{Generation of NOD. $\alpha 4-/-$ Mice}

Hematopoietic specific ablation of the $\alpha 4$ integrin under the control of the tie 2 promoter was described previously [24]. Tie2Cre+ and $\alpha 4 \mathrm{f} / \mathrm{f}$ mice were individually inbred into the NOD background for 10 generations. NOD strain background was confirmed using whole genome screening (Figure $\mathrm{S} 1 \mathrm{~A}$ ); the strains we then crossed to generate NOD. $\alpha 4 \mathrm{f} / \mathrm{fTie} 2 \mathrm{cre}+$ (NOD. $\alpha 4-/-)$ mice (Figure S1B,C for genotyping strategy and exemplary results). NOD. $\alpha 4-/-$ mice were efficiently $\alpha 4$ ablated in the hematopoietic lineage, specifically also on T-cells (Figure S1D). Albeit being born at slightly less than Mendelian ratios, NOD. $\alpha 4-/-$ were normal-sized and healthy-appearing. 
The $\alpha 4-/-$ cellular immune system was previously tested and its overall functionality confirmed for C57Bl/6 mice, although several models of autoimmune disease were markedly attenuated in $\alpha 4-/-$ mice [40,41]. We assessed distribution of T-cells in NOD. $\alpha 4-/-$ blood and spleen of naïve, effector and memory cells in both cytotoxic and helper cell compartments, as well as relative frequency of T-cells (Figure S2A-C) and found them to be very similar in NOD and NOD. $\alpha 4-/-$ cells. Both strains also had similar numbers of NK cells (Figure S2D). The $\alpha 4-/$ - humoral immune system has received less attention; for NOD. $\alpha 4-/-$ mice, here we show quantitatively normal B-cell maturation in spleen, blood and bone marrow (BM) (Figure S3A-C, respectively) as well as demonstrating-in an innovative murine immunization model-that $\alpha 4$-deficiency does not impair the humoral immune response including B-memory function per se (Figure S3D), although antibody titers were significantly lower in NOD. $\alpha 4-/-$ than in NOD mice $(p<0.05)$.

\subsection{NOD.a4-/- Mice Are Protected from Autoimmune Diabetes}

Twenty female NOD. $\alpha 4-/$ - mice and all concurrent female NOD (wild-type; $n=62$ ) or NOD. $\alpha 4+/$ ( $\alpha 4$ haplo-insufficent; $n=59$ ) mice were continuously accrued and observed for a total of 40 weeks for development of T1D. NOD and NOD. $\alpha 4+/$ - became diabetic with indistinguishable kinetics $(p=$ n.s.), with the first mice manifesting at 9-10 weeks of age, reaching peak cumulative incidence of $75-80 \%$ at age 40 weeks and dying or requiring painless killing within 1-3 weeks of diabetes onset. By contrast, NOD. $\alpha 4-/-$ mice were completely protected from diabetes (cumulative incidence, $0 \% ; p<0.001$ (lLog-rank test) vs. NOD and NOD. $\alpha 4+/-;$ Figure 1A). Because of the absence of a distinctive (e.g., attenuated) phenotype of the $\alpha 4$ haplo-insufficient mice, all further experiments considered haplo-insufficient mice as $\alpha 4$-competent. Henceforth, we will solely distinguish between NOD ( $\alpha 4$-competent) and NOD. $\alpha 4-/-$ mice.

\subsection{Adaptive Cellular and Humoral Immune Responses of NOD. $\alpha 4-$ - Mice against Islet Cell Antigens}

In spite of their diabetes resistance, NOD. $\alpha 4-/$ - mice tested positive for both circulating islet-antigen specific cytotoxic T-cells (Figure 1B) and islet autoantibodies (Figure 1C), albeit both quantitatively significantly less than the $\alpha 4$-competent counterparts ( $p<0.05$ for both). However, these islet-antigen specific $\alpha 4-/$ - T-cells were apparently incapable of infiltrating islets, while $\alpha 4$ competent NOD mice showed significant insulitis already at the age of 8 weeks of life (Figure 2A,B and Figure 3A,B; NOD. $\alpha 4-/-$ vs. pre-diabetic 8 week-old NOD $(p=0.0037)$, vs. newly diabetic $(p=0.0006)$ and vs. longer-term diabetic ( $p=0.0007)$ NOD mice; comparison of the three NOD cohorts with one another: $p=0.097-0.47$, n.s.). NOD. $\alpha 4-/-$ mice were also protected from the characteristic autoimmune sialitis which in NOD mice was characterized by large T-lymphocyte infiltrates at young adult age and eventually progressed to virtually complete destruction of the acini (Figure $2 \mathrm{C}, \mathrm{D}$ and Figure $4 \mathrm{~A}, \mathrm{~B} ; p<0.001$ ).

3.4. Adoptive Transfer of a Mix of Diabetogenic $\alpha 4+$ Helper and Cytotoxic T-Cells, but Not $\alpha 4+$ Helper T-Cells Alone, Induce Diabetes in NOD. $\alpha 4-/-$ Mice

Our knock-out mice provided the opportunity to perform some unique adoptive immune transfer experiments that could not be addressed with anti-functional antibodies. Using NOD or NOD. $\alpha 4-/-$ mice as recipients of negatively selected CD3+ splenocytes from diabetic mice, both recipient groups developed diabetes within two (NOD) or four (NOD. $\alpha 4-/-)$ weeks. The delay was statistically significant (Figure 1D; $p<0.05$ ). When the diabetic NOD. $\alpha 4-/$ - hosts were bled, their pancreata were harvested, and host vs. donor T-cells were analyzed, T-cells isolated from islets were exclusively donor-derived, i.e., $\alpha 4+$, despite representing only a minor fraction (13.6\%) of T cells in the blood (Figure S4). We next tested the ability of $\alpha 4+/ C D 4+$ spleen T-cells to cause diabetes, with a most remarkable outcome: all NOD hosts developed diabetes, as before with very short latency, while NOD. $\alpha 4-/$ - recipients were completely protected (Figure 1E; $p<0.01$ ). 
A

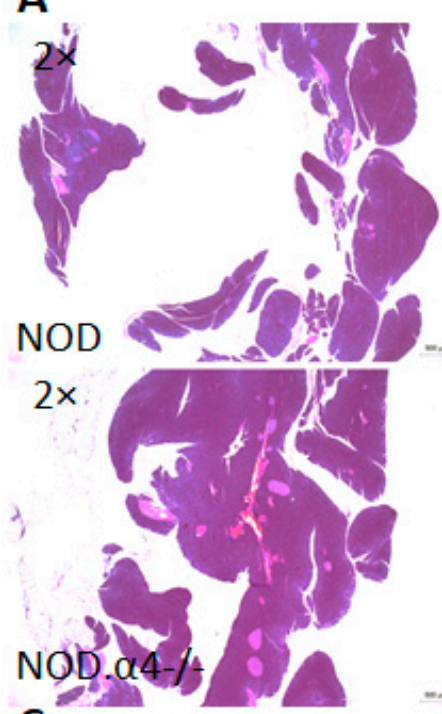

C

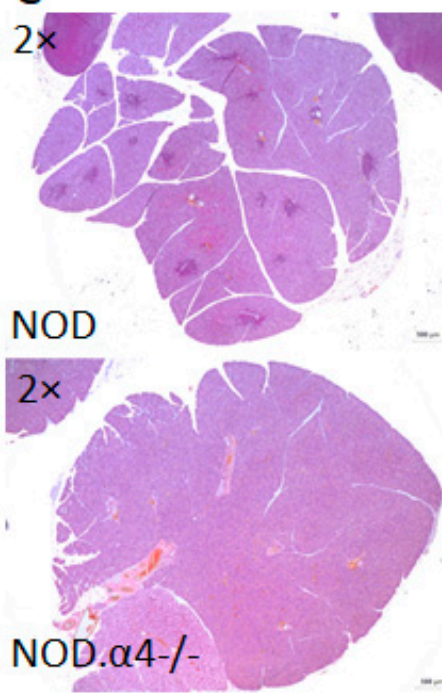

B
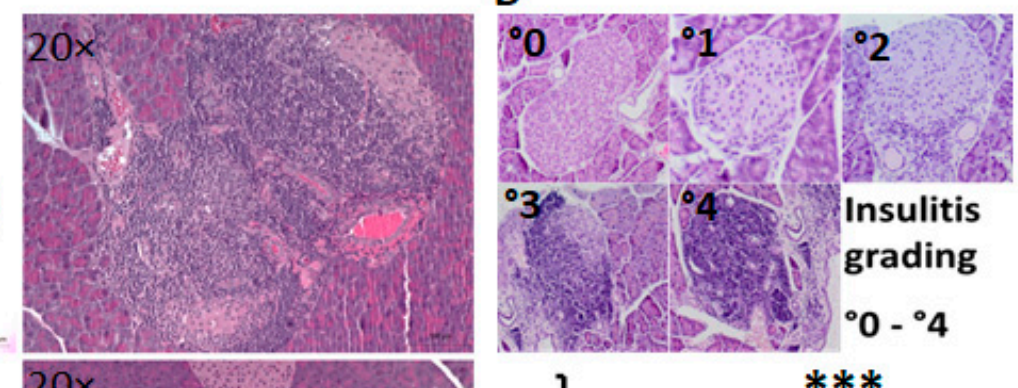

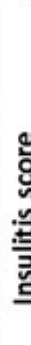

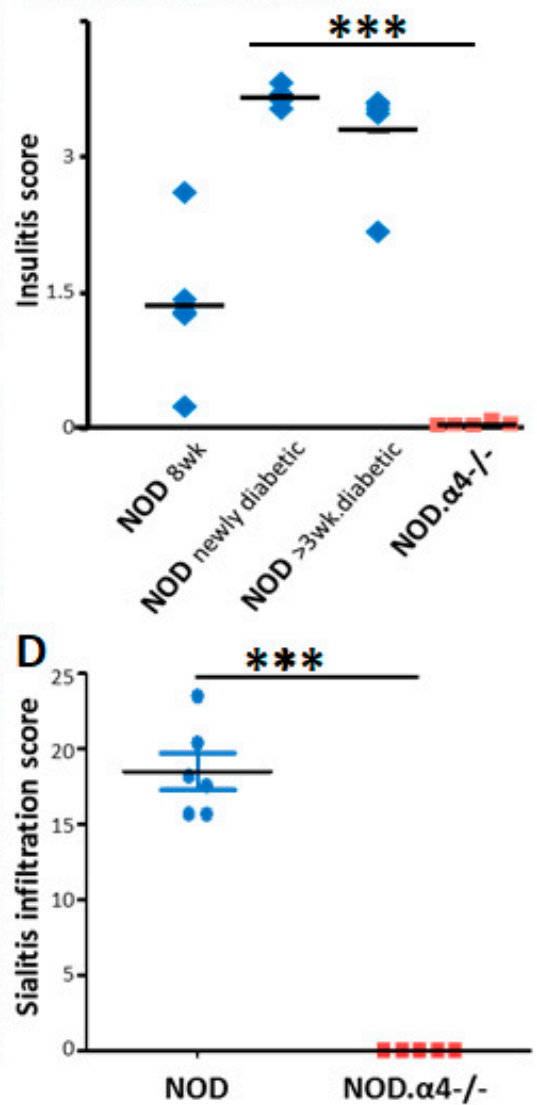

Figure 2. Histological analysis of pancreas islets and submandibular glands. Histological evaluation of lymphocyte infiltration of pancreas islets $(\mathbf{A}, \mathbf{B})$ and submandibular glands (C,D). Exemplary appearance of diabetic NOD or age-matched NOD. $\alpha 4-/$ - pancreas (A) and quantitative analysis of insulitis severity in the indicated groups $(\mathbf{B})$. Each dot represents the average insulitis score from multiple non-consecutive sections from one animal, the bar marking the mean $(\mathrm{n}=5$ (NOD) to 8 (NOD. $\alpha 4-/-)$ animals per group; $p<0.005$ for NOD. $\alpha 4-/-$ vs. each of the NOD groups, $p=$ n.s. between NOD groups). Inset images of islets in (B) exemplify the 5-grade histological scoring system between 0 and 4 . Exemplary appearance of NOD or NOD. $\alpha 4-/-$ submandibular glands (C) and enumeration of sialitis score (D). Each dot represents the average sialitis score from multiple non-consecutive sections from one animal, the bar marking the mean $(n=5-6$ animals per group; $p<0.001)$. Asterisks indicate statistical significance at the $\left.0.005{ }^{* * *}\right)$ level. 
A
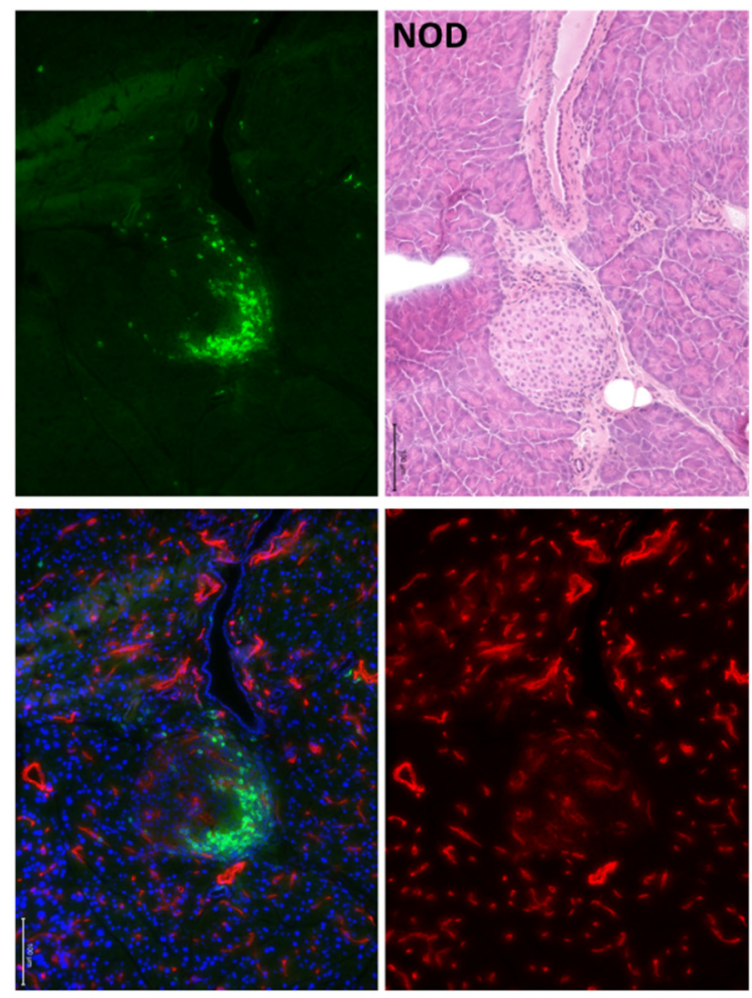

B
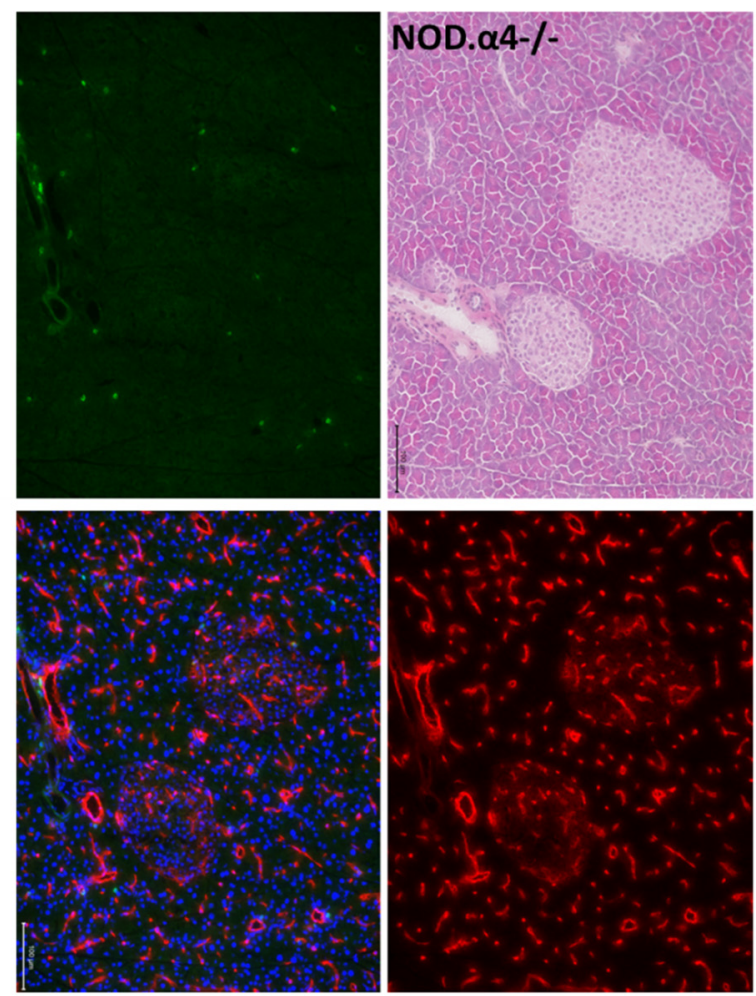

Figure 3. Pancreas immunofluorescence histology of young adult non-diabetic mice. Pancreas from NOD (A) and NOD. $\alpha 4-/-(B)$ young adults is shown, with a prominent lymphocyte infiltrate in (A). Adjacent sections were used for hematoxylin-eosin (HE) or immunohistochemistry staining (CD3: green, Meca32: red, merged fluorescence image including DAPI; 20× original magnification; $100 \mu \mathrm{m}$ size bars in image).

\section{5. $\alpha 4$ Ablation Protects Pre-Diabetic NOD Mice from Diabetes}

As $\alpha 4$ blockade is efficacious in established autoimmune disease like multiple sclerosis and inflammatory bowel disease in humans, we furthermore asked whether $\alpha 4$ ablation could also prevent autoimmune diabetes in young adult pre-diabetic NOD mice, i.e., in mice with established insulitis but with residual islet cell function and thus still normoglycemic. Eight to ten week-old female NOD hosts were radio-conditioned followed by transplantation with young female $\alpha 4$ competent non-diabetic NOD or NOD. $\alpha 4-/-$ bone marrow. Both engrafted promptly and completely, and recipients of $\alpha 4$ competent NOD bone marrow developed diabetes with similar kinetics and cumulative incidence as for spontaneous NOD diabetes. Thus, in agreement with published work [42], lethal irradiation and transplantation by itself does not affect the outcomes as most NOD bone marrow recipients became diabetic 12-25 weeks after transplantation. All NOD mice reconstituted with $\alpha 4-/$ - hematopoiesis, in contrast, remained diabetes-free (Figure 1F; $p<0.001$ ).

\subsection{Pre-Diabetic NOD Mice Have Normal Microbiota}

Altered microbiota have been described in several autoimmune disorders including diabetes. Whether the autoimmune disease is a cause or consequence of the dysbiosis remains unclear [43-45]. Our model afforded us the unique opportunity to co-house $\alpha 4$-competent and -deficient mice. Over time, some of the $\alpha 4$-competent ones eventually became diabetic. Mice exhibiting coprophagia, co-housing were expected to result in maximally similar microbiota. Indeed non-diabetic (or more precisely, pre-diabetic) NOD and diabetes-resistant NOD. $\alpha 4-/-$ mice had essentially indistinguishable microbiota. Similarity extended to both $\alpha$-diversity (Shannon $\alpha$-diversity; $p=0.75$ ) and abundance or absence 
of certain components. By contrast, $\alpha$-diversity was markedly restricted in diabetic NOD mice ( $p=0.02$ and 0.04 compared to non-diabetic NOD and NOD. $\alpha 4-/-$ mice, respectively, Figure 5A). Moreover, certain genera were completely extinct, such as Ruminococcus, Prevotella and Candidatus Saccharimonas, or over-represented (Bacteroidales S24-7 group) in the feces of diabetic NOD mice (Analysis of Composition of Microbiomes (ANCOM) scores 0.7 or greater for all; Figure 5B-E).

A
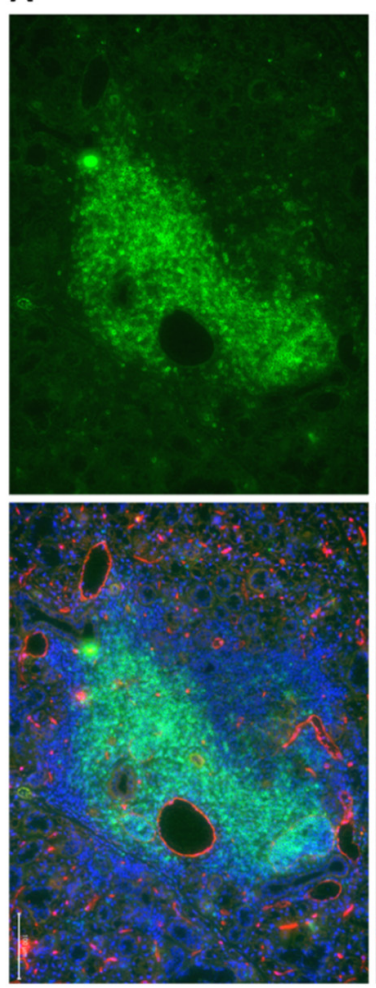
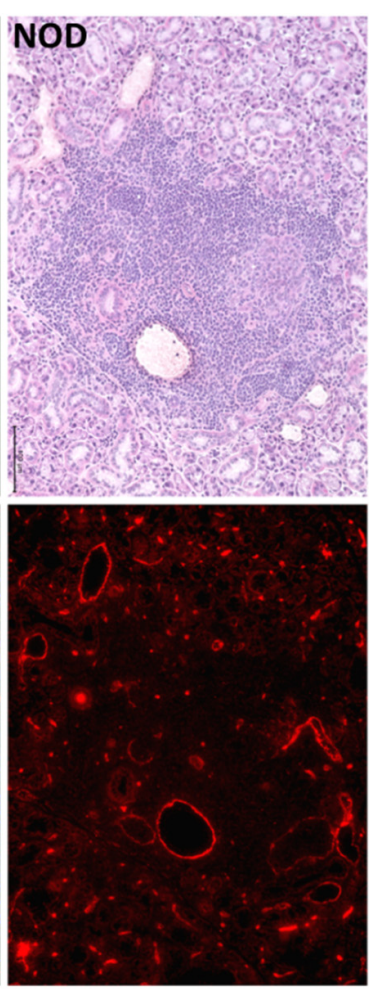

B

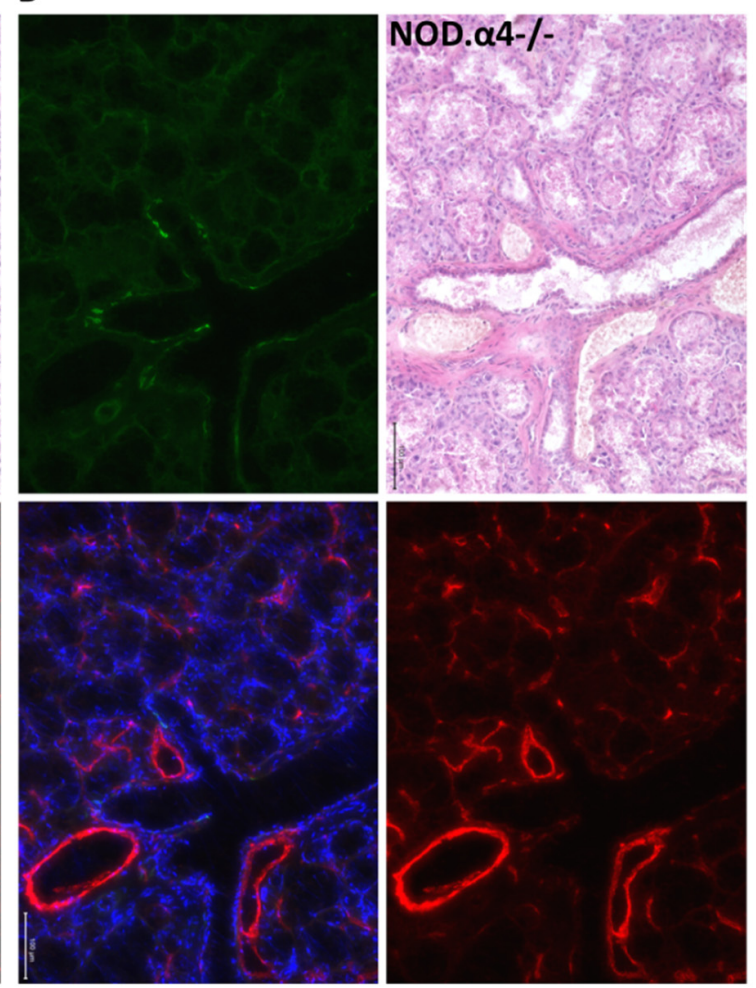

Figure 4. Submandibular gland immunofluorescence histology of young adult non-diabetic mice. Submandibular gland from NOD (A) and NOD. $\alpha 4-/-(B)$ young adults is shown, with a prominent lymphocyte infiltrate in (A). Adjacent sections were used for $\mathrm{HE}$ or immunohistochemistry staining (CD3: green, Meca32: red, merged fluorescence image including DAPI; 20× original magnification; $100 \mu \mathrm{m}$ size bars in image).
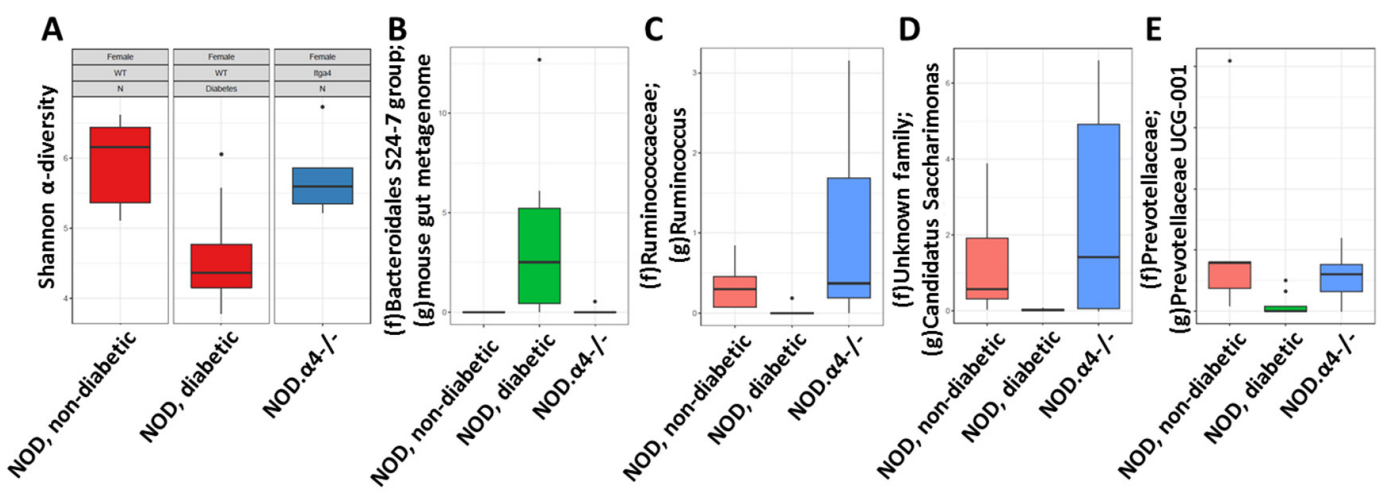

Figure 5. Microbiota analysis. Feces from 5 non-diabetic NOD, 5 NOD. $\alpha 4-/-$ and 9 diabetic NOD mice were subjected to microbiota analyses. Microbiota diversity of diabetic mice was restricted (Shannon $\alpha$-diversity $p<0.05$ diabetic NOD compared to both non-diabetic groups; $p=n$.s. between non-diabetic NOD and NOD. $\alpha 4-/-)(\mathbf{A})$ and marked by appearance (B), extinction (C,D) or quantitative depletion (E) of unique taxa (ANCOM score $\geq 0.7$ for all four; box plot marking interquartile range and median; Dots mark outlier values). 


\section{Discussion}

Several studies reported effects of anti-functional anti-integrin antibodies in mice which experiments with genetic models subsequently unraveled as artifacts (for a recent example, see: [46]). Therefore, although work with anti- functional antibodies in NOD mice [15,19-21] had in principle indicated contributions of $\alpha 4$ integrin to insulitis and diabetes (although their magnitude was discussed controversially), we sought to reappraise the issue with an NOD. $\alpha 4$ knock-out mouse. Furthermore, the knock-out mouse could address certain questions which were inaccessible with anti-functional antibodies or had previously remained unanswered. Specifically, hematopoietic integrin knock-out mice allow the separation of effects of circulating vs. resident and hematopoietic vs. stromal cells, as well as interrogation of contributions of isolated sub-populations. The unique, or novel, insight provided by the newly generated NOD. $\alpha 4-/-$ mouse is discussed below.

For one, certain short-comings of published studies with xenogeneic anti-functional antibodies in NOD mice [15,19-21] could not be ruled out by the design of the published studies, including immunological reactions which could cause anti-diabetic inflammatory responses or opsonization and lymphodepletion, or simple pharmacological effects such as dosing and dose interval. In the published work, protection was mostly only relative and highly variable between studies; the $n$ in most studies was small $[15,21]$. As we are conclusively showing in a large cohort, $\alpha 4$ ablation affords perfect protection from T1D and autoimmune insulitis, thus, definitively validating prior work with our distinct experimental approach (Figures $1 \mathrm{~A}$ and $2 \mathrm{~A}, \mathrm{~B}$ ).

Secondly, some tools for more mechanistic assessment of anti-islet immune responses were until quite recently not available so that earlier work regarding $\alpha 4$ in T1D had predominantly provided phenotypic analyses $[15,19-21]$. Using MHC multimer reagents (H-2Kd with peptide VYLKTNVFL from IGRP), we clearly identified islet antigen-specific T-cells in NOD. $\alpha 4-/-$ mice. To study the NOD. $\alpha 4-/$ - humoral immune system, we developed a novel, highly sensitive, specific and quantitative immunization model. The assay informs of the principle ability of the mice to initiate adaptive humoral responses and to establish humoral memory. Indeed we know that patients treated with anti-functional anti- $\alpha 4$ antibodies are capable of B-cell responses [47]. The attenuated humoral response to the immunization observed here (Figure S3D) is proportionally reflected by the reduced islet autoantibody titers (Figure 1C). Thus, $\alpha 4$ deficiency prevents neither cellular nor humoral responses against islet autoantigens. Instead, $\alpha 4-/-$ T-cells fail to migrate into the target tissue (Figure 2A,B and Figure S4). The observation teaches that adaptive immunity against islet antigens arises in extra-pancreatic compartments and is not critically dependent on $\alpha 4$ integrin. Moreover, islet autoantibodies by themselves do not induce diabetes. This conclusion is in line with clinical observations in patients with established MS and IBD, where therapeutic $\alpha 4$-blockade remains effective in the presence of significant numbers of antigen-specific T-cells in and inflammation of target tissues [16-18,47]. With our transplant experiments, whereby pre-diabetic $\alpha 4+$ recipients were made diabetes-resistant with transplants from NOD. $\alpha 4-/$ - donors, we extend this paradigm to T1D (Figure 1F).

Thirdly, a genetic model can target integrins on selected immune cell species as opposed to the invariably ubiquitous inhibition achieved by antibodies. We thus performed some unique experiments with mixed chimeras for $\alpha 4+$ and $\alpha 4-/-$ T-cells. Transfer of $\alpha 4+$ splenocytes from diabetic donors to NOD or NOD. $\alpha 4-/$ - mice induced diabetes with $100 \%$ penetrance, albeit with a marked delay in the NOD. $\alpha 4-/-$ mice (Figure 1D). We take this temporal delay to indicate differential recruitment velocity of autoaggressive T-cells to inflamed (in the pre-diabetic $\alpha 4+$ recipients) vs. bland (in the $\alpha 4-/$ - recipients) islets. Alternative or complimentary explanations for the differential kinetics of adoptively transferred diabetes include overall more rapid activation and proliferation of these T-cells in the inflammatory milieu of the pre-diabetic NOD mouse although one might expect the radiation-induced inflammation to override subtle systemic effects of insulitis. Possibly, reduced islet cell reserve in pre-diabetic hosts can contribute to relative disease acceleration, less optimal interaction with contributing $\alpha 4-/-$ than with WT non-T-host cells to slight attenuation. Importantly, although markedly under-represented in 
blood, all T-cells recovered from pancreata of these mixed chimeras were $\alpha 4+$ (Figure S4). Thus, even inflamed islets infiltrated with $\alpha 4+$ T-cells cannot co-recruit $\alpha 4-/-T$-cells.

While transfer of diabetic donor CD8+ cells alone cannot elicit diabetes [48], a highly variable diabetogenic potential of diabetic donor $\mathrm{CD} 4+$ cells has been reported [48-51]. In some cases, co-injected contaminating CD8+ T-cells could be imputed [49]. Importantly, these data were generated with immunodeficient NOD/SCID hosts which lack endogenous lymphocytes which the donor cells could coopt and whose antigen presentation is defective [52]. From these data, Janeway et al. conclude that although in principle CD4+ T-cells are capable of T1D induction, this process is much more efficient in the presence of CD8+ T cells [48]. In our immunocompetent NOD hosts, transfer of highly purified CD4+ cells from diabetic donors caused diabetes in all $\alpha 4+$, yet none of the $\alpha 4-/$ - recipients. Thus CD4+ T-cells are actually quite efficient at inducing diabetes if they can recruit and instruct additional $\alpha 4+$ host immune cells, presumably CD8+ lymphocytes. $\alpha 4-/-$ immune cells, whether innate or adaptive, cannot support $\alpha 4+/ \mathrm{CD} 4+$ to induce islet cell destruction.

Fourth, the reciprocal relationship between host and gut microbiota has been the focus of a significant body of recent work [43-45]. The association of a given disease with recurrent alterations of the microbiota has sometimes been interpreted as indicative of a causal relationship: According to that hypothesis, the aberrant microbiota was hypothesized to arise spontaneously and to exacerbate the pathology [53,54]. Clearly, dysbiosis with pathogenic bacteria can attenuate diabetes proneness in the NOD mouse [55]. Our NOD. $\alpha 4-/-$ mice afforded the opportunity to study the microbiota in unperturbed co-housed pre-diabetic, newly diabetic or diabetes- resistant NOD mice. We pursued two aims, the first seeking to ascertain whether a universal "diabetic microbiota" exists, by comparing our data with published work in other diabetes models [43-45,53-56]. Secondly, our genetic model should be able to answer the question of cause and causality of diabetes and dysbiosis. Indeed, we observed a marked dysbiosis in the diabetic NOD mice, with significantly reduced diversity and selection/de-selection of certain bacterial genera (Figure 3). Both lack of diversity and the specific changes in the microbiota are similar in nature and magnitude, and they also affect some of the same genera as were previously reported for other diabetes models [43-45,53-56]. Common denominators include the appearance of Bacteroidales and extinction of Prevotella in diabetic NOD mice $[53,54,56]$. Pre-diabetic and diabetes-resistant NOD mice's microbiota, however, was indistinguishable. Thus the "diabetic" flora only establishes itself once the mice are hyperglycemic. The scientific community is currently beginning to understand nutrient preference of microbial taxa in situ; apparently certain gut metabolites select or de-select specific microbes. Thus, Cand. Saccharimonas, extinguished from the microbiota of the diabetic hosts, [57] negatively correlates with methylamine in stool, with methylamine being a product of amine catabolism which is increased in diabetes. The aggregate evidence thus suggests that in the model presented here, abnormal microbiota is consequence, not a cause of diabetes in NOD mice, likely secondary to an altered fecal metabolome.

Fifth, our model conclusively demonstrates for the first time the critical dependence on $\alpha 4$ integrin for development of autoimmune sialitis in NOD mice. In earlier work $[19,20]$, administration of $\alpha 4$-blocking antibody for the first four weeks of life had failed to affect frequency and severity of sialitis at 42 weeks of age. Since the same antibody regimen had provided long-term protection from diabetes, the authors had thus concluded about $\alpha 4$-independence of NOD sialitis. The probable explanation for these divergent findings is that likely long-term $\alpha 4$-blockade is required to prevent sialitis.

Sixth, protection of pre-diabetic recipients of $\alpha 4$-negative hematopoietic transplants documents the potential of $\alpha 4$-targeted therapy to prevent diabetes even after sensitization and islet cell infiltration have occurred, i.e., in a clinically relevant scenario. Similar experiments in new-onset diabetic mice failed due to the rapid disease progression after diagnosis. 
Short-comings of the NOD model as a model of human T1D deserve brief mentioning. The strain is characterized by numerous immunological defects, including aberrant down-regulation of MHC in response to IFN $\gamma$ [58], apoptosis-deficient lymphocytes [59], abnormal function of antigen-presenting cells and natural killer-cell dysfunction [60], as well as complement C5 deficiency [61], together translating into a general defect in the development of regular immune tolerance [62]. Possibly in part due to these abnormalities, but also due to a timing which is hard to reproduce in humans, i.e., long before diabetes onset [9], of the long list of interventions capable of attenuating diabetes risk in NOD mice most have failed to be confirmed in humans [9]. With respect to $\alpha 4$ we believe, however, that the ability of $\alpha 4$-blocking antibody to modify the course of certain established autoimmune diseases predicts that the situation may be different. We thus predict that $\alpha 4$ blockade during pre-diabetes (after islet-specific autoantibodies can be detected) or even in recent-onset diabetes can be arrested or reversed. Alternative animal models of spontaneous diabetes, most famously the biobreeder (BB) rat [63], have been described, each with their own idiosyncrasies, but for the work presented here the NOD model appears to be meaningfully informative.

\section{Conclusions}

In summary, we show that NOD. $\alpha 4-/-$ mice are diabetes resistant despite developing adaptive immunity, albeit attenuated, against islet cell autoantigens. Transfer of diabetogenic CD4+T-cells did not cause diabetes in NOD. $\alpha 4-/-$ mice. Diabetic NOD mice have a "diabetic" microbiota which is markedly distinct from the microbiota of co-housed pre-diabetic NOD and NOD. $\alpha 4-/-$ mice, implying that in the absence of external selection pressure on the microbiome (e.g., with antibiotics), host factors-likely nutritional—select the microbiota. NOD. $\alpha 4-/-$ mice are protected against autoimmune sialitis. The data provided in this paper have immediate translational potential, since relatively safe, tolerable and highly effective $\alpha 4$-targeting reagents of pharmaceutical quality, i.e., the anti-functional anti- $\alpha 4$-antibody Natalizumab, are readily available. Certainly during the pre-diabetic phase characterized by normoglycemia with circulating islet antigen antibodies, $\alpha 4$-blockade would be expected to provide secondary diabetes prevention. We also posit that therapeutic $\alpha 4$-blockade in children with recent-onset diabetes will be able to preserve the residual islet cell mass and allow for its regeneration, thus at least delaying T1D until a less fragile age, ideally beyond puberty.

Supplementary Materials: The following are available online at http:/www.mdpi.com/2073-4409/9/12/2597/s1, Figure S1: Generation of NOD. $\alpha 4-/-$ mice, Figure S2: T- and NK-cells in NOD and NOD. $\alpha 4-/-$ mice, Figure S3: B-cell maturation and function, Figure S4: Adoptive transfer of CD3+ T-cells from diabetic NOD donors causes insulitis but fails to recruit $\alpha 4-/$ - T-cells to islets.

Author Contributions: S.O. designed and performed experiments, interpreted results, generated figures and co-wrote the manuscript. S.K.W. designed and performed experiments and interpreted results, G.S., N.M. and A.S. performed experiments. S.H. performed experiments and generated figures. T.P. provided critical reagents and co-wrote the manuscript. H.B. designed experiments and interpreted results, co-wrote the manuscript, provided funding and bears the overall responsibility for the work. T.P. and H.B. conceived of the idea for the research. All authors have read and agreed to the published version of the manuscript.

Funding: The work was partly funded through a Marie Curie International Reintegration Grant from the European Union, grant \#200876, to HB. SO was supported by a scholarship from Avicenna Studienwerk e.V.

Conflicts of Interest: The authors declare that the research was conducted in the absence of any commercial or financial relationships that could be construed as a potential conflict of interest.

\section{References}

1. Gale, E.A. The rise of childhood type 1 diabetes in the 20th century. Diabetes 2002, 51, 3353-3361. [CrossRef]

2. Patterson, C.C.; Dahlquist, G.G.; Gyurus, E.; Green, A.; Soltesz, G. Incidence trends for childhood type 1 diabetes in Europe during 1989-2003 and predicted new cases 2005-20: A multicentre prospective registration study. Lancet 2009, 373, 2027-2033. [CrossRef] 
3. Steffes, M.W.; Sibley, S.; Jackson, M.; Thomas, W. Beta-cell function and the development of diabetes-related complications in the diabetes control and complications trial. Diabetes Care 2003, 26, 832-836. [CrossRef] [PubMed]

4. Streisand, R.; Monaghan, M. Young children with type 1 diabetes: Challenges, research, and future directions. Curr. Diab. Rep. 2014, 14, 520. [CrossRef] [PubMed]

5. Keenan, H.A.; Sun, J.K.; Levine, J.; Doria, A.; Aiello, L.P.; Eisenbarth, G.; Bonner-Weir, S.; King, G.L. Residual insulin production and pancreatic ss-cell turnover after 50 years of diabetes: Joslin Medalist Study. Diabetes 2010, 59, 2846-2853. [CrossRef] [PubMed]

6. Willcox, A.; Richardson, S.J.; Bone, A.J.; Foulis, A.K.; Morgan, N.G. Analysis of islet inflammation in human type 1 diabetes. Clin. Exp. Immunol. 2009, 155, 173-181. [CrossRef] [PubMed]

7. Smukler, S.R.; Arntfield, M.E.; Razavi, R.; Bikopoulos, G.; Karpowicz, P.; Seaberg, R.; Dai, F.; Lee, S.; Ahrens, R.; Fraser, P.E.; et al. The adult mouse and human pancreas contain rare multipotent stem cells that express insulin. Cell Stem Cell 2011, 8, 281-293. [CrossRef]

8. Dor, Y.; Brown, J.; Martinez, O.I.; Melton, D.A. Adult pancreatic beta-cells are formed by self-duplication rather than stem-cell differentiation. Nature 2004, 429, 41-46. [CrossRef]

9. Shoda, L.K.; Young, D.L.; Ramanujan, S.; Whiting, C.C.; Atkinson, M.A.; Bluestone, J.A.; Eisenbarth, G.S.; Mathis, D.; Rossini, A.A.; Campbell, S.E.; et al. A comprehensive review of interventions in the NOD mouse and implications for translation. Immunity 2005, 23, 115-126. [CrossRef]

10. Bonifacio, E.; Ziegler, A.G. Advances in the prediction and natural history of type 1 diabetes. Endocrinol. Metab. Clin. N. Am. 2010, 39, 513-525. [CrossRef]

11. Podolsky, D.K.; Lobb, R.; King, N.; Benjamin, C.D.; Pepinsky, B.; Sehgal, P.; Debeaumont, M. Attenuation of colitis in the cotton-top tamarin by anti-alpha 4 integrin monoclonal antibody. J. Clin. Investig. 1993, 92, 372-380. [CrossRef] [PubMed]

12. Yednock, T.A.; Cannon, C.; Fritz, L.C.; Sanchez-Madrid, F.; Steinman, L.; Karin, N. Prevention of experimental autoimmune encephalomyelitis by antibodies against alpha 4 beta 1 integrin. Nature 1992, 356, 63-66. [CrossRef] [PubMed]

13. Banerjee, E.R.; Jiang, Y.; Henderson, W.R., Jr.; Latchman, Y.; Papayannopoulou, T. Absence of alpha 4 but not beta 2 integrins restrains development of chronic allergic asthma using mouse genetic models. Exp. Hematol. 2009, 37, 715-727. [CrossRef] [PubMed]

14. Mulligan, M.S.; Johnson, K.J.; Todd, R.F.; Issekutz, T.B.; Miyasaka, M.; Tamatani, T.; Smith, C.W.; Anderson, D.C.; Ward, A.P. Requirements for leukocyte adhesion molecules in nephrotoxic nephritis. J. Clin. Investig. 1993, 91, 577-587. [CrossRef]

15. Baron, J.L.; Reich, E.P.; Visintin, I.; Janeway, C.A., Jr. The pathogenesis of adoptive murine autoimmune diabetes requires an interaction between alpha 4-integrins and vascular cell adhesion molecule-1. J. Clin. Investig. 1994, 93, 1700-1708. [CrossRef]

16. Sandborn, W.J.; Feagan, B.G.; Rutgeerts, P.; Hanauer, S.; Colombel, J.F.; Sands, B.E.; Lukas, M.; Fedorak, R.N.; Lee, S.; Bressler, B.; et al. Vedolizumab as induction and maintenance therapy for Crohn's disease. N. Engl. J. Med. 2013, 369, 711-721. [CrossRef]

17. Polman, C.H.; O'Connor, P.W.; Havrdova, E.; Hutchinson, M.; Kappos, L.; Miller, D.H.; Phillips, J.T.; Lublin, F.D.; Giovannoni, G.; Wajgt, A.; et al. A randomized, placebo-controlled trial of natalizumab for relapsing multiple sclerosis. N. Engl. J. Med. 2006, 354, 899-910. [CrossRef]

18. Feagan, B.G.; Rutgeerts, P.; Sands, B.E.; Hanauer, S.B.; Colombel, J.-F.; Sandborn, W.J.; Van Assche, G.; Axler, J.; Kim, H.-J.; Danese, S.; et al. Vedolizumab as induction and maintenance therapy for ulcerative colitis. N. Engl. J. Med. 2013, 369, 699-710. [CrossRef]

19. Yang, X.D.; Karin, N.; Tisch, R.; Steinman, L.; McDevitt, H.O. Inhibition of insulitis and prevention of diabetes in nonobese diabetic mice by blocking L-selectin and very late antigen 4 adhesion receptors. Proc. Natl. Acad. Sci. USA 1993, 90, 10494-10498. [CrossRef]

20. Yang, X.D.; Michie, S.A.; Tisch, R.; Karin, N.; Steinman, L.; McDevitt, H.O. A predominant role of integrin alpha 4 in the spontaneous development of autoimmune diabetes in nonobese diabetic mice. Proc. Natl. Acad. Sci. USA 1994, 91, 12604-12608. [CrossRef]

21. Kommajosyula, S.; Reddy, S.; Nitschke, K.; Kanwar, J.R.; Karanam, M.; Krissansen, G.W. Leukocytes infiltrating the pancreatic islets of nonobese diabetic mice are transformed into inactive exiles by combinational anti-cell adhesion therapy. J. Leukoc. Biol. 2001, 70, 510-517. [PubMed] 
22. Yang, X.D.; Michie, S.A.; Tisch, R.; Karin, N.; Steinman, L.; McDevitt, H.O. Cell adhesion molecules: A selective therapeutic target for alleviation of IDDM. J. Autoimmun. 1994, 7, 859-864. [CrossRef] [PubMed]

23. Yang, X.D.; Sytwu, H.K.; McDevitt, H.O.; Michie, S.A. Involvement of beta 7 integrin and mucosal addressin cell adhesion molecule-1 (MAdCAM-1) in the development of diabetes in obese diabetic mice. Diabetes 1997, 46, 1542-1547. [CrossRef] [PubMed]

24. Scott, L.M.; Priestley, G.V.; Papayannopoulou, T. Deletion of alpha4 integrins from adult hematopoietic cells reveals roles in homeostasis, regeneration, and homing. Mol. Cell Biol. 2003, 23, 9349-9360. [CrossRef] [PubMed]

25. Koni, P.A.; Joshi, S.K.; Temann, U.A.; Olson, D.; Burkly, L.; Flavell, R.A. Conditional vascular cell adhesion molecule 1 deletion in mice: Impaired lymphocyte migration to bone marrow. J. Exp. Med. 2001, 193, 741-754. [CrossRef]

26. Chudziak, D.; Spohn, G.; Karpova, D.; Dauber, K.; Wiercinska, E.; Miettinen, J.A.; Papayannopoulou, T.; Bonig, H. Functional consequences of perturbed CXCL12 signal processing: Analyses of immature hematopoiesis in GRK6-deficient mice. Stem Cells Dev. 2015, 24, 737-746. [CrossRef]

27. Barclay, A.N.; Brown, M.H. Heterogeneity of interactions mediated by membrane glycoproteins of lymphocytes. Biochem. Soc. Trans. 1997, 25, 224-228. [CrossRef]

28. Janeway, C.A., Jr. The T cell receptor as a multicomponent signalling machine: CD4/CD8 coreceptors and CD45 in T cell activation. Annu. Rev. Immunol. 1992, 10, 645-674. [CrossRef]

29. Walzer, T.; Chiossone, L.; Chaix, J.; Calver, A.R.; Carozzo, C.; Garrigue-Antar, L.; Jacques, Y.; Baratin, M.; Tomasello, E.; Vivier, E. Natural killer cell trafficking in vivo requires a dedicated sphingosine 1-phosphate receptor. Nat. Immunol. 2007, 8, 1337-1344. [CrossRef]

30. Chee, J.; Ko, H.-J.; Skowera, A.; Jhala, G.; Catterall, T.; Graham, K.L.; Sutherland, R.M.; Thomas, H.E.; Lew, A.M.; Peakman, M.; et al. Effector-Memory T Cells Develop in Islets and Report Islet Pathology in Type 1 Diabetes. J. Immunol. 2014, 192, 572-580. [CrossRef]

31. Allman, D.; Lindsley, R.C.; DeMuth, W.; Rudd, K.; Shinton, S.A.; Hardy, R.R. Resolution of Three Nonproliferative Immature Splenic B Cell Subsets Reveals Multiple Selection Points During Peripheral B Cell Maturation. J. Immunol. 2001, 167, 6834-6840. [CrossRef] [PubMed]

32. Hardy, R.R.; Carmack, C.E.; Shinton, S.A.; Kemp, J.D.; Hayakawa, K. Resolution and characterization of pro-B and pre-pro-B cell stages in normal mouse bone marrow. J. Immunol. 1991, 189, 3271-3283. [CrossRef] [PubMed]

33. Li, D.S.; Yuan, Y.H.; Tu, H.J.; Liang, Q.L.; Dai, L.J. A protocol for islet isolation from mouse pancreas. Nat. Protoc. 2009, 4, 1649-1652. [CrossRef] [PubMed]

34. Hansen, C.H.; Yurkovetskiy, L.A.; Chervonsky, A.V. Cutting Edge: Commensal Microbiota Has Disparate Effects on Manifestations of Polyglandular Autoimmune Inflammation. J. Immunol. 2016, 197, 701-705. [CrossRef] [PubMed]

35. Callahan, B.J.; McMurdie, P.J.; Rosen, M.J.; Han, A.W.; Johnson, A.J.; Holmes, S.P. DADA2: High-resolution sample inference from Illumina amplicon data. Nat. Methods 2016, 13, 581-583. [CrossRef]

36. Katoh, K.; Standley, D.M. MAFFT multiple sequence alignment software version 7: Improvements in performance and usability. Mol. Biol. Evol. 2013, 30, 772-780. [CrossRef]

37. Price, M.N.; Dehal, P.S.; Arkin, A.P. FastTree 2-approximately maximum-likelihood trees for large alignments. PLoS ONE 2010, 5, e9490. [CrossRef]

38. Quast, C.; Pruesse, E.; Yilmaz, P.; Gerken, J.; Schweer, T.; Yarza, P.; Peplies, J.; Glöckner, F.O. The SILVA ribosomal RNA gene database project: Improved data processing and web-based tools. Nucleic Acids Res. 2013, 41, D590-D596. [CrossRef]

39. Lozupone, C.; Lladser, M.E.; Knights, D.; Stombaugh, J.; Knight, R. UniFrac: An effective distance metric for microbial community comparison. ISME J. 2011, 5, 169-172. [CrossRef]

40. Ulyanova, T.; Priestley, G.V.; Banerjee, E.R.; Papayannopoulou, T. Unique and redundant roles of alpha4 and beta2 integrins in kinetics of recruitment of lymphoid vs myeloid cell subsets to the inflamed peritoneum revealed by studies of genetically deficient mice. Exp. Hematol. 2007, 35, 1256-1265. [CrossRef]

41. Banerjee, E.R.; Jiang, Y.; Henderson, W.R., Jr.; Scott, L.M.; Papayannopoulou, T. Alpha4 and beta2 integrins have nonredundant roles for asthma development, but for optimal allergen sensitization only alpha4 is critical. Exp. Hematol. 2007, 35, 605-617. [CrossRef] [PubMed] 
42. Steptoe, R.J.; JRitchie, M.; Harrison, L.C. Transfer of hematopoietic stem cells encoding autoantigen prevents autoimmune diabetes. J. Clin. Investig. 2003, 111, 1357-1363. [CrossRef] [PubMed]

43. Knip, M.; Siljander, H. The role of the intestinal microbiota in type 1 diabetes mellitus. Nat. Rev. Endocrinol. 2016, 12, 154-167. [CrossRef] [PubMed]

44. Giongo, A.; Gano, K.A.; Crabb, D.B.; Mukherjee, N.; Novelo, L.L.; Casella, G.; Giongo, A.; Gano, K.A.; Crabb, D.B.; Mukherjee, N.; et al. Toward defining the autoimmune microbiome for type 1 diabetes. ISME J. 2011, 5, 82-91. [CrossRef]

45. de Goffau, M.C.; Luopajarvi, K.; Knip, M.; Ilonen, J.; Ruohtula, T.; Harkonen, T.; Orivuori, L.; Hakala, S.; Welling, G.W.; Harmsen, H.J.; et al. Fecal microbiota composition differs between children with beta-cell autoimmunity and those without. Diabetes 2013, 62, 1238-1244. [CrossRef]

46. Ulyanova, T.; Georgolopoulos, G.; Papayannopoulou, T. Reappraising the role of alpha5 integrin and the microenvironmental support in stress erythropoiesis. Exp. Hematol. 2020, 81, 16-31. [CrossRef] [PubMed]

47. Traub, J.W.; Pellkofer, H.L.; Grondey, K.; Seeger, I.; Rowold, C.; Brück, W.; Husseini, L.; Häusser-Kinzel, S.; Weber, M.S. Natalizumab promotes activation and pro-inflammatory differentiation of peripheral B cells in multiple sclerosis patients. J. Neuroinflamm. 2019, 16, 228. [CrossRef]

48. Wong, F.S.; Janeway, C.A., Jr. The role of CD4 vs. CD8 T cells in IDDM. J. Autoimmun. 1999, 13, $290-295$. [CrossRef]

49. Christianson, S.W.; Shultz, L.D.; Leiter, E.H. Adoptive transfer of diabetes into immunodeficient NOD-scid/scid mice. Relative contributions of CD4+ and CD8+ T-cells from diabetic versus prediabetic NOD.NON-Thy-1a donors. Diabetes 1993, 42, 44-55. [CrossRef]

50. Bendelac, A.; Carnaud, C.; Boitard, C.; Bach, J.F. Syngeneic transfer of autoimmune diabetes from diabetic NOD mice to healthy neonates. Requirement for both L3T4+ and Lyt-2+ T cells. J. Exp. Med. 1987, 166, 823-832. [CrossRef]

51. Miller, B.J.; Appel, M.C.; O’Neil, J.J.; Wicker, L.S. Both the Lyt-2+ and L3T4+ T cell subsets are required for the transfer of diabetes in nonobese diabetic mice. J. Immunol. 1988, 140, 52-58. [PubMed]

52. Shultz, L.D.; Schweitzer, P.A.; Christianson, S.W.; Gott, B.; Schweitzer, I.B.; Tennent, B.; McKenna, S.; Mobraaten, L.; Rajan, T.V.; Greiner, D.L.; et al. Multiple defects in innate and adaptive immunologic function in NOD/LtSz-scid mice. J. Immunol. 1995, 154, 180-191. [PubMed]

53. Brown, C.T.; Davis-Richardson, A.G.; Giongo, A.; Gano, K.A.; Crabb, D.B.; Mukherjee, N.; Casella, G.; Drew, J.C.; Ilonen, J.; Knip, M.; et al. Gut microbiome metagenomics analysis suggests a functional model for the development of autoimmunity for type 1 diabetes. PLoS ONE 2011, 6, e25792. [CrossRef] [PubMed]

54. Knip, M.; Honkanen, J. Modulation of Type 1 Diabetes Risk by the Intestinal Microbiome. Curr. Diab. Rep. 2017, 17, 105. [CrossRef]

55. King, C.; Sarvetnick, N. The incidence of type-1 diabetes in NOD mice is modulated by restricted flora not germ-free conditions. PLoS ONE 2011, 6, e17049. [CrossRef]

56. Krych, L.; Nielsen, D.S.; Hansen, A.K.; Hansen, C.H. Gut microbial markers are associated with diabetes onset, regulatory imbalance, and IFN-gamma level in NOD mice. Gut Microbes 2015, 6, 101-109. [CrossRef]

57. Lin, H.; An, Y.; Hao, F.; Wang, Y.; Tang, H. Correlations of Fecal Metabonomic and Microbiomic Changes Induced by High-fat Diet in the Pre-Obesity State. Sci. Rep. 2016, 6, 21618. [CrossRef]

58. Leiter, E.H. The NOD mouse: A model for analysing the interplay between heredity and environment in development of autoimmune disease. ILAR News 1993, 35, 4. [CrossRef]

59. Leijon, K.; Hammarstrom, B.; Holmberg, D. Non-obese diabetic (NOD) mice display enhanced immune responses and prolonged survival of lymphoid cells. Int. Immunol. 1994, 6, 339. [CrossRef]

60. Serreze, D.V.; Leiter, E.H. Defective activation of T suppressor cell function in nonobese diabetic mice. Potential relation to cytokine deficiencies. J. Immunol. 1988, 140, 3801.

61. Baxter, A.G.; Cooke, A. Complement lytic activity has no role in the pathogenesis of autoimmune diabetes in NOD mice. Diabetes 1993, 42, 1574. [CrossRef]

62. Markees, T.G.; Serreze, D.V.; Phillips, N.E.; Sorli, C.H.; Gordon, E.J.; Shultz, L.D.; Noelle, R.J.; Greiner, B.A.W.D.L.; Mordes, J.P.; Rossini, A.A. NOD mice have a generalized defect in their response to transplantation tolerance induction. Diabetes 1999, 48, 967. [CrossRef] 
63. Nakhooda, A.F.; Like, A.A.; Chappel, C.J.; Murray, F.T.; Marliss, E.B. The spontaneously diabetic Wistar rat: Metabolic and morphologic studies. Diabetes 1977, 26, 100. [CrossRef]

Publisher's Note: MDPI stays neutral with regard to jurisdictional claims in published maps and institutional affiliations.

(C) 2020 by the authors. Licensee MDPI, Basel, Switzerland. This article is an open access article distributed under the terms and conditions of the Creative Commons Attribution (CC BY) license (http://creativecommons.org/licenses/by/4.0/). 